\title{
Coal Contractor Mining Facts - 2003
}

The Mine Safety and Health Administration (MSHA) defines an independent contractor as "any person, partnership, corporation, subsidiary of a corporation, firm, association or other organization that contracts to perform services or construction at a mine." Contractors that perform specific types of work are required to report the number of employees who perform work at coal mines and at noncoal mines.

1. In 2003, a total of 2,633 contracting companies reported employment at coal mines to MSHA.

2. A total of 28,672 coal contractor employees, corresponding to 16,098 full-time equivalent (FTE) employees, were reported to MSHA in 2003. This represents a 4.1\% decrease in FTE coal contractor employees from $2002 .{ }^{1}$

- The highest percentage of coal contractor employees was found in surface production operations (63.2\%), followed by preparation plants (25.1\%) and underground operations $(11.7 \%)^{2}$

3. Eight work-related fatalities occurred among coal contractor employees in 2003, compared to seven in 2002.

- In 2003, coal contractor employees had a fatality rate of 49.7 fatalities per 100,000 FTE employees, compared to a fatality rate of 29.2 fatalities per 100,000 FTE coal operator employees.

- The underground work location fatality rate was 212.8 per 100,000 FTE employees in $2003(n=4)$ compared to the 2002 fatality rate of $142.2(n=3)$.

- The fatality rate for preparation plants was 74.2 per 100,000 FTE employees $(n=3)$ and 9.8 per 100,000 FTE employees for surface work locations $(n=1)$.

4. There were 441 nonfatal lost-time injuries among coal contractor employees occurring at a rate of 2.7 injuries per 100 FTEs in 2003. A total of 32,809 days lost from work resulted from these injuries. ${ }^{3}$

- For coal contractor employees, the median number of days lost from work as a result of nonfatal lost-time injuries was 22. The median was 31 days for coal mine operator employees.

- The highest injury rate among coal contractor employees was found in underground coal operations (9.9 injuries per 100 FTE employees).

- The most frequently reported types of accidents among coal contractor employees were handling material $(n=154 ; 34.9 \%)$ and slips or falls $(n=108 ; 24.5 \%)$. Among the most frequently reported types of accident (greater than $10 \%$ of total), the most severe injuries (as measured by the median number of days lost) were associated with powered haulage $(n=54$, median $=42.5)$.

- Sprains and strains were the most frequently reported nature of injury $(n=166)$, resulting in 12,561 days lost from work.

- The back was the most frequently reported body part injured $(n=83,18.8 \%)^{4}$

- Among coal contractor employees, those with the MSHA job title of "laborer/utilityman/bull gang" had the greatest number of nonfatal lost-time injuries ( $n=111 ; 25.2 \%$ ).

5. Thirteen cases of occupational illness in coal contractor employees were reported to MSHA in $2003 .^{5}$ There were five cases of black lung (coal workers' pneumoconiosis); four cases of joint, tendon, or muscle inflammation or irritation; two cases of hearing impairment; and one case each of dermatitis and heat stroke.

Note: All analyses exclude office employees.

${ }^{1}$ Computed using reported employee hours $(2,000$ hours $=1 \mathrm{FTE})$.

${ }^{2}$ Surface production operations include strip mines, surface operations at underground mines, preparation plants, mills, auger mining, culm banks, dredge, and surface shops and yards.

${ }^{3}$ Includes actual days away from work and/or days of restricted work activity. For permanently disabling injuries only, statutory days charged by MSHA were used if they exceeded the total lost workdays.

${ }^{4}$ MSHA only reports the most severely injured part of body for accidents involving injury to multiple body parts.

${ }^{5}$ Because of the complexity of attributing disease causation to the workplace, occupational illnesses may be underreported. 


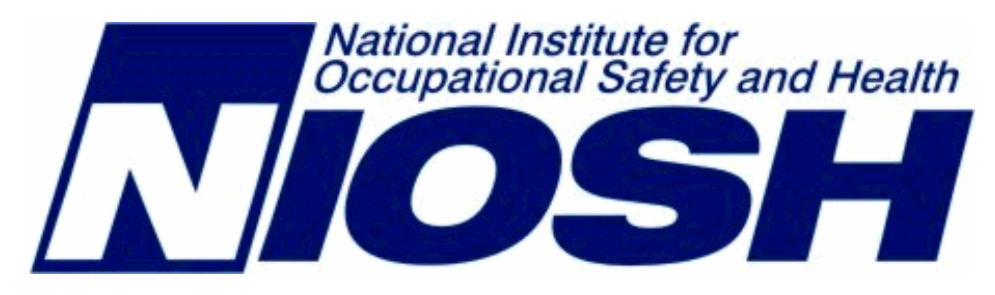

Delivering on the Nation's promise:

Safety and health at work for all people through research and prevention

For information about occupational safety and health topics contact NIOSH at:

1-800-35-NIOSH (1-800-356-4674)

Fax: 513-533-8573

e-mail: pubstaft@cdc.gov

www.cdc.gov/niosh

\section{SAFER • HEALTHIER • PEOPLE ${ }^{T M}$}

